\title{
Correlation between vaulting intraoperative and postoperative of EVO implantable Collamer lens: a retrospective study of real-time observations of vaulting using the RESCAN 700 system
}

Nian Guan

Wuhan Bright Eye Hospital

Xiao-Nong Zhang

Wuhan Bright Eye Hospital

Wan-Jun Zhang (D8688560@qq.com)

Hefei Bright Eye Hospital

\section{Research Article}

Keywords: lenses, intraocular; lens implantation, intraocular, tomography, optical coherence, refractive surgery, post-operative vault.

Posted Date: December 29th, 2020

DOI: https://doi.org/10.21203/rs.3.rs-123289/v1

License: (c) (i) This work is licensed under a Creative Commons Attribution 4.0 International License.

Read Full License

Version of Record: A version of this preprint was published at BMC Ophthalmology on January 3rd, 2022. See the published version at https://doi.org/10.1186/s12886-021-02237-2. 


\section{Abstract}

Background: The prediction of implantable Collamer lens (ICL) vaulting is one of the most important parameters for ICL implantation for safety, aqueous humor circulation, and lens transparency.

Methods: This was a retrospective study. A RESCAN 700 was used for intraoperative observation of vaulting. Spectral-domain optical coherence tomography was used for imaging.

Results: Finally, 51 patients (102 eyes) were included in the study. Compared with the eyes with normal vaulting, those with high vaulting had higher preoperative diopter values $(P=0.039)$, lower preoperative corrected visual acuity $(P=0.006)$, lower preoperative intraocular pressure $(P=0.029)$, higher preoperative anterior chamber depth $(P=0.004)$, lower preoperative crystalline lens rise $(P=0.046)$, higher ICL spherical equivalent $(P=0.030)$, higher intraoperative vaulting $(P<0.001)$, and lower intraocular pressure at 1 month $(P=0.045)$. The multivariable analysis showed that the only factors independently associated with high vaulting at 1 month after surgery was the intraoperative vaulting value (odds ratio $=1.005,95 \%$ confidence interval: $1.002-1.007, \mathrm{P}<0.001)$. The intraoperative and 1-month postoperative vaulting values were correlated $\left(R^{2}=0.562\right)$.

Conclusions: The RESCAN700 system can be used to perform intraoperative optical coherence tomography to predict the vaulting value at 1 month.

\section{Background}

Refractive errors of the eye are common conditions and include myopia (worldwide prevalence of 1.45 billion [1]), hyperopia (worldwide prevalence of $30.9 \%$ in adults [2]), and astigmatism (worldwide prevalence of $40.4 \%$ in adults [2]). Those errors arise when the images are not clearly focused on the retina due to the eyeball length and shape of the cornea. Corrective glasses or contact lenses are the most common methods used to achieve better vision.

Implantable Collamer lens (ICL) is another option for the correction of refractive errors. The Visian ICL ${ }^{\mathrm{Tm}}$ (STAAR Surgical, Nidau, Switzerland) is a posterior chamber phakic intraocular lens (IOL) [3-5]. The EVOICL is based on an artificial hole and achieves acceptable safety [6], and is similar to traditional ICLs in terms of high-order aberrations and contrast sensitivity [7]. Nevertheless, the most challenging parameter in ICL implantation is the accurate prediction of vaulting, and precise and optimal vaulting is the key parameter for successful ICL implantation [8]. An improper vaulting can lead to adverse events such as pupillary block, iris touch, angle-closure glaucoma, anterior lens opacification, and early cataract [9-11]. About $2.6 \%$ of implanted ICL have improper vaulting and require exchange [12-16].

Previous methods for determining vaulting involved white-to-white measurement (manually or with imaging systems) or sulcus-to-sulcus measurement using high-frequency ultrasound have been the main methods for vaulting prediction $[17,18]$. Later, optical coherence tomography (OCT) was added to refine the prediction [19-21]. Recent OCT systems that are built within the operating microscope now allow for 
more precise eye surgeries [22-24]. Only a few studies examined the use of intraoperative OCT for the determination of ICL vaulting [25]. Of note, a recent multivariable model explains only $34 \%$ of the variability of lens vaulting among individuals [26]. Hence, additional studies are necessary to refine the prediction of ICL vaulting.

This study aimed to explore the factors associated with the actual vaulting after refractive EVO-ICL surgery and the correlation between intraoperative vaulting and the actual vaulting at 1 month after surgery, in order to determine whether OCT device during surgery could provide some clinical help. The results might help a better prediction of ICL vaulting and avoid the need for early ICL exchange.

\section{Methods}

\section{Study design and patients}

This was a retrospective study of patients who underwent EVO-ICL surgery at Wuhan Bright Eye Hospital between October and December 2019. This study was approved by the Ethics Committee of this Hospital. The written informed consent was obtained from all patients.

The inclusion criteria were: 1 ) age: $21-45$ years; 2 ) anterior chamber depth (ACD) $>2.8 \mathrm{~mm} ; 3$ ) corneal endothelial cell density (ECD) $>2000 / \mathrm{mm}^{2}$; and 4) completed EVO-ICL surgery and follow-up in this hospital. The exclusion criteria were: 1 ) other eye diseases such as cataracts and glaucoma that caused visual loss; 2) systemic diseases such as diabetes, autoimmune diseases, or collagen diseases that could affect postoperative healing; or 3 ) being unable to measure vaulting due to unclear intraoperative OCT images.

\section{Preoperative Measurement}

The preoperative diopter, corrected visual acuity (CVA), white-to-white distance (WTW), IOP, ACD, anterior chamber volume (ACV), crystalline lens rise (CLR), axial length, and ECD were recorded. During surgery, the RESCAN 700 system (Carl Zeiss GmbH, Oberkochen, Germany) was used to measure EVO-ICL vaulting. Uncorrected visual acuity (UCVA) and best-corrected visual acuity (BCVA) were checked using an international standard visual acuity chart (converted into logMAR visual acuity).

Subjective and objective refractions were performed using a CV-5000 comprehensive refractometer (Topcon Corporation, Tokyo, Japan). The anterior ocular segment was determined using an SL-115 Classic slit lamp microscope (Carl Zeiss $\mathrm{GmbH}$, Oberkochen, Germany). A Pentacam HR threedimensional panoramic analyzer for the anterior segment (Oculus, Wetzlar, Germany) was used to check corneal morphology, ACV, CLR, and WTW. A CT-800 non-contact tonometer (Topcon Corporation, Tokyo, Japan) was used to measure IOP. An IOL Master 700 biometer (Carl Zeiss GmbH, Oberkochen, Germany) was used to measure ACD and axial length. An SP-3000P corneal endothelial cell counter (Topcon Corporation, Tokyo, Japan) was used to measure corneal ECD. Fundoscopy was performed using a V90C non-contact slit lamp pre-set lens (Halma plc, Amersham, UK). Intraoperative vaulting was observed by using a RESCAN700 microscope (Carl Zeiss GmbH, Oberkochen, Germany). SD-OCT was used for scan 
imaging, and the ImageJ software was used to measure the ICL vault value. A CIRRUS HD-OCT (Carl Zeiss $\mathrm{GmbH}$, Oberkochen, Germany) was used to measure the distance between the posterior surface of the EVO-ICL and the anterior lens capsule, namely the vault value. All measurements were performed by an ophthalmologist with 9 years of professional experience.

\section{EVO-ICL Surgery}

All procedures were performed by the same ophthalmologist with 4 years of professional experience. The size of the EVO-ICL was determined based on WTW, ACD, ACV, and CLR. The online system provided by the manufacturer was used to calculate the EVO-ICL diopter (STAAR Surgical Co., Monrovia, CA, USA). At 3 days before surgery, levofloxacin eye drops (Santen Pharmaceutical Co., Ltd., Osaka, Japan) were continuously administrated at 4 times/day. At 30 min before surgery, compound tropicamide eye drops (Santen Pharmaceutical Co., Ltd., Osaka, Japan) were used for mydriasis. Oxybuprocaine hydrochloride eye drops (Santen Pharmaceutical Co., Ltd., Osaka, Japan) were used to perform surface anesthesia. The axis of corneal astigmatism was marked under the slit lamp before surgery. Conventional disinfection and draping were conducted. The conjunctival sac was washed. The main incision was made at the steepest meridian of the cornea. A syringe was used to inject the EVO-ICL into the anterior chamber. An appropriate amount of $15 \mathrm{mg} / \mathrm{ml}$ medical sodium hyaluronate gel (Hangzhou Singclean Medical Products Co., Ltd., Hangzhou, China) was injected above the EVO-ICL to maintain the ACD. The four angles of the EVO-ICL were adjusted to the ciliary sulcus behind the iris with the adjustment hook, and the EVO-ICL was adjusted to the marked area and the residual viscoelastic in the anterior chamber. An Icare rebound tonometer (Icare Finland Oy, Vantaa, Finland) was used to measure the IOP, which was controlled at $15-18 \mathrm{mmHg}$ by replenishing and releasing aqueous humor. A RESCAN 700 microscope (Carl Zeiss AG, Oberkochen, Germany) was used to perform the SD-OCT scan imaging. The five-line scanning mode was used, with a scanning depth of $2.0 \mathrm{~mm}$ and a scanning length of $2.0 \mathrm{~mm}$. The distance between the posterior surface of EVO-ICL and anterior lens capsule was observed, and the snapshot mode was used to save the screenshot after clearing. After the end of the surgery, tobramycin dexamethasone eye drops (Alcon-Couvreur SA, Puurs, Belgium) were used.

\section{Intraoperative Measurement Of Vaulting}

A RESCAN 700 (Carl Zeiss AG, Oberkochen, Germany) was used for intraoperative imaging, and SD-OCT was used for scanning imaging. For intraoperative SD-OCT image export, the ImageJ software (version 1.48) was used for processing, and the scanning depth was adjusted to $2.0 \mathrm{~mm}$. The distance between the posterior surface of EVO-ICL and anterior lens capsule was measured. All measurements were conducted three times, and the average values were recorded, namely the intraoperative vaulting values.

\section{Follow-up}

All patients were followed routinely at 1 month after surgery. The distance between the posterior surface of the EVO-ICL and anterior lens capsule (namely, the vaulting value) was measured using a CIRRUS HDOCT (Carl Zeiss AG, Oberkochen, Germany). Under the same indoor light, all measurements were 
performed by the same ophthalmologist three times, and the average values were recorded. For the vault at 1 month after surgery, $250-750 \mu \mathrm{m}$ was defined as normal vaulting, $<250 \mu \mathrm{m}$ as low vaulting, and $>$ $750 \mu \mathrm{m}$ as high vaulting $[27,28]$. At the same time, visual acuity, IOP, and diopter were measured.

\section{Statistical analysis}

SPSS 22.0 (IBM Corp., Armonk, NY, USA) was used for data processing and statistical analyses. Normally distributed continuous data (according to the Kolmogorov-Smirnov test) were presented as means \pm standard deviations and analyzed using Student's t-test. Non-normally distributed data were presented as medians (ranges) and analyzed using the Mann-Whitney U-test. Categorical data were presented as frequencies (percentage) and analyzed using the chi-square test or Fisher's exact test. For the multivariable analysis, high vaulting at 1 month after surgery was used as the dependent variable, and the factors with between-group differences $(P<0.05)$ in the univariable analyses (enter method) were used as the independent variables. Binary logistic regression analysis was performed. Linear correlation analysis was performed regarding the intraoperative and postoperative vaulting. Two-sided (except for the chi-square test) P-values $<0.05$ were considered statistically significant.

\section{Results}

\section{Characteristics of the patients}

A total of 56 patients with 112 eyes were enrolled. Among them, vaulting could not be measured in five patients (10 eyes) by intraoperative OCT. Finally, 51 patients (102 eyes) were included in the study (Fig. 1). There were two (2.0\%) eyes with low vaulting postoperatively, and two (2.0\%) eyes underwent lens exchange due to high vaulting. Figure 2 presents typical vaulting measurements. Given there were only two patients with low vaulting, this study analyzed patients with normal vaulting and those with high vaulting.

Table 1 presents the characteristics of the patients. Compared with the eyes with normal vaulting, those with high vaulting had higher preoperative diopter values $(P=0.039)$, lower preoperative CVA $(P=0.006)$, lower preoperative IOP $(P=0.029)$, higher preoperative ACD $(P=0.004)$, lower preoperative CLR $(P=$ $0.046)$, higher ICL spherical equivalent $(S E)(P=0.030)$, higher intraoperative vaulting $(P<0.001)$, and lower IOP at 1 month $(P=0.045)$. 
Table 1

Characteristics of the patients

\begin{tabular}{|c|c|c|c|c|}
\hline Characteristics & $\begin{array}{l}\text { All }(n= \\
100)\end{array}$ & $\begin{array}{l}\text { Normal } \\
\text { vaulting ( } n= \\
67)\end{array}$ & $\begin{array}{l}\text { High vaulting } \\
(n=33)\end{array}$ & $\mathbf{P}$ \\
\hline Sex (male), n (\%) & $35(35)$ & $26(38.8)$ & $9(27.3)$ & 0.256 \\
\hline Age (years), median (range) & $\begin{array}{l}25.5 \\
(21,40)\end{array}$ & $26(21,40)$ & $25(21,39)$ & 0.680 \\
\hline $\begin{array}{l}\text { Preoperative diopter SE (D), median } \\
\text { (range) }\end{array}$ & $\begin{array}{l}-8.5 \\
(-18,-2.8)\end{array}$ & $-8.4(-18,-2.8)$ & $-8.8(-18,-5)$ & 0.039 \\
\hline $\begin{array}{l}\text { Preoperative CVA (LogMar), median } \\
\text { (range) }\end{array}$ & $0(0,0.5)$ & $0(0,0.5)$ & $0(0,0.4)$ & 0.006 \\
\hline Preoperative IOP (mmHg), median (range) & $18(13,22)$ & $19(13,22)$ & $17(14,21)$ & 0.029 \\
\hline Preoperative ACD (mm), median (range) & $\begin{array}{l}3.2 \\
(2.8,3.7)\end{array}$ & $3.1(2.8,3.7)$ & $3.4(2.8,3.7)$ & 0.004 \\
\hline Preoperative ACV $(\mu \mathrm{L})$, median (range) & $\begin{array}{l}205 \\
(128,562)\end{array}$ & $204(131,562)$ & $\begin{array}{l}217 \\
(128,307)\end{array}$ & 0.172 \\
\hline $\begin{array}{l}\text { Preoperative axial length }(\mathrm{mm}) \text {, mean } \pm \\
\text { SD }\end{array}$ & $26.8 \pm 1.3$ & $26.7 \pm 1.3$ & $27.1 \pm 1.1$ & 0.080 \\
\hline Preoperative corneal ECD, mean \pm SD & $\begin{array}{l}2914.1 \pm \\
233.7\end{array}$ & $2910.3 \pm 263.2$ & $2922 \pm 161.2$ & 0.785 \\
\hline Preoperative WTW (mm), median (range) & $\begin{array}{l}11.7 \\
(10.7,12.6)\end{array}$ & $\begin{array}{l}11.6 \\
(10.7,12.5)\end{array}$ & $\begin{array}{l}11.8 \\
(10.8,12.6)\end{array}$ & 0.091 \\
\hline Preoperative CLR $(\mu \mathrm{m})$, median (range) & $\begin{array}{l}210 \\
(0,520)\end{array}$ & $230(0,520)$ & $190(0,390)$ & 0.046 \\
\hline ICL size $(\mathrm{mm}), \mathrm{n}(\%)$ & & & & 0.175 \\
\hline 121 & $4(4)$ & $3(4.5)$ & $1(3)$ & \\
\hline 126 & $38(38)$ & $30(44.8)$ & $8(24.2)$ & \\
\hline 132 & $52(52)$ & $30(44.8)$ & $22(66.7)$ & \\
\hline 137 & $6(6)$ & $4(6)$ & $2(6.1)$ & \\
\hline ICL degree SE (D), median (range) & $\begin{array}{l}-9.5 \\
(-18,-3.5)\end{array}$ & $-9.5(-18,-3.5)$ & $-10(-18,-5.5)$ & 0.030 \\
\hline
\end{tabular}

Spherical equivalent $=$ sphere power plus $1 / 2$ cylinder power

SE: spherical equivalent; CVA: corrected visual acuity; IOP: intraocular pressure; ACD: Anterior chamber depth; ACV: anterior chamber volume: ECD: Endothelial cell density; WTW: White-to-white distance; CLR: crystalline lens rise. 


\begin{tabular}{|c|c|c|c|c|}
\hline Characteristics & $\begin{array}{l}\text { All }(n= \\
100)\end{array}$ & $\begin{array}{l}\text { Normal } \\
\text { vaulting }(n= \\
67)\end{array}$ & $\begin{array}{l}\text { High vaulting } \\
(n=33)\end{array}$ & $\mathbf{P}$ \\
\hline Intraoperative vaulting $(\mu \mathrm{m})$, mean $\pm S D$ & $\begin{array}{l}770.7 \pm \\
323.5\end{array}$ & $657.2 \pm 279.3$ & $\begin{array}{l}1001.2 \pm \\
284.8\end{array}$ & $\begin{array}{l}< \\
0.001\end{array}$ \\
\hline $\begin{array}{l}\text { Vaulting at } 1 \text { month after surgery }(\mu \mathrm{m}) \text {, } \\
\text { median (range) }\end{array}$ & $\begin{array}{l}634 \\
(252,1650)\end{array}$ & $560(252,730)$ & $\begin{array}{l}910 \\
(760,1650)\end{array}$ & $<0.001$ \\
\hline $\begin{array}{l}\text { Visual acuity at } 1 \text { month after surgery } \\
\text { (LogMar), median (range) }\end{array}$ & $\begin{array}{l}-0.1 \\
(-0.2,0.4)\end{array}$ & $-0.1(-0.2,0.4)$ & $-0.1(-0.2,0.2)$ & 0.284 \\
\hline $\begin{array}{l}\text { Diopter SE at } 1 \text { month after surgery (D), } \\
\text { median (range) }\end{array}$ & $\begin{array}{l}0.3 \\
(-1.5,1.3)\end{array}$ & $0.3(-1.5,1.3)$ & $0.3(-0.3,1)$ & 0.127 \\
\hline $\begin{array}{l}\text { IOP ( } \mathrm{mmHg} \text { ) at } 1 \text { month after surgery, } \\
\text { median (range) }\end{array}$ & $18(13,23)$ & $18(13,23)$ & $17(14,21)$ & 0.045 \\
\hline \multicolumn{5}{|c|}{ Spherical equivalent $=$ sphere power plus $1 / 2$ cylinder power } \\
\hline \multicolumn{5}{|c|}{$\begin{array}{l}\text { SE: spherical equivalent; CVA: corrected visual acuity; IOP: intraocular pressure; ACD: Anterior } \\
\text { chamber depth; ACV: anterior chamber volume: ECD: Endothelial cell density; WTW: White-to-white } \\
\text { distance; CLR: crystalline lens rise. }\end{array}$} \\
\hline
\end{tabular}

\section{Multivariable Analysis}

Based on the univariable analyses, preoperative diopter, preoperative CVA, preoperative IOP, preoperative $A C D$, preoperative CLR, ICL degree SE, and intraoperative vaulting were entered in the multivariable analysis (Table 2). The multivariable analysis showed that the only factors independently associated with high vaulting at 1 month after surgery was the intraoperative vaulting value (Table 2). 
Table 2

Independent influencing factors of high vaulting at 1 month after the operation

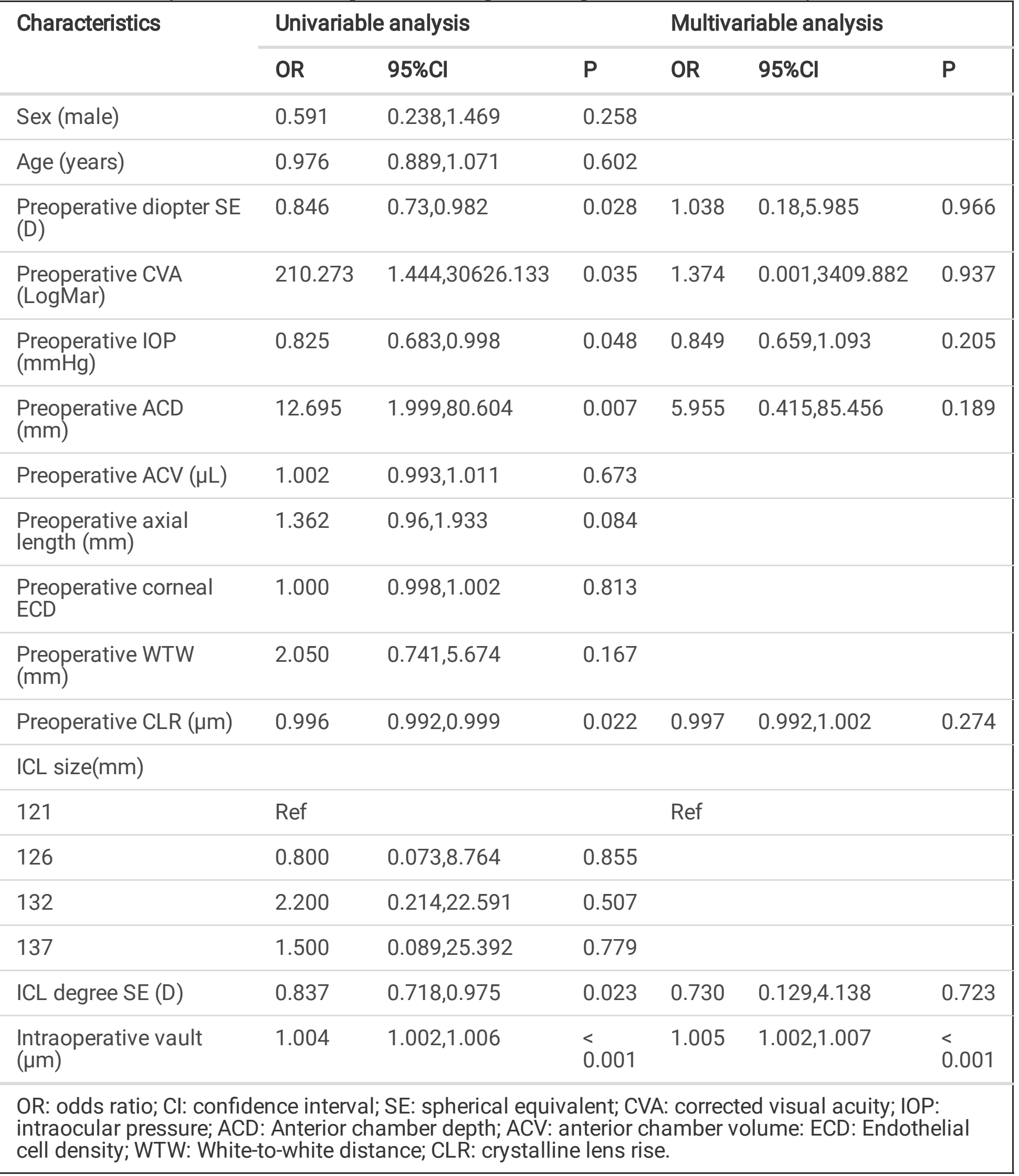


The results of the linear correlation analysis of intraoperative and postoperative vaulting are shown in Fig. 3. The correlation was significant $\left(R^{2}=0.562\right)$.

\section{Discussion}

The prediction of ICL vaulting is one of the most important parameters for ICL implantation. This study aimed to explore the factors associated with actual vaulting after EVO-ICL implantation and the correlation between intraoperative and 1-month vaulting using OCT. The results strongly suggest that the RESCAN700 system can be used to perform intraoperative OCT to predict the vaulting value at 1 month. Taking into account the correlation between intraoperative and 1-month vaulting, optimization interventions can be carried out in time to obtain better results when abnormal intraoperative vaulting was observed.

The RESCAN 700 is the latest generation of operating microscopes integrating the LUEMRA microscope platform and OCT. It can be used to perform real-time observations of OCT images during surgery. Currently, studies reported the use of the RESCAN 700 system in vitreoretinal surgery, corneal transplantation, and cataract surgery [29-33]. Only one recent study used the RESCAN 700 to examine the vaulting after ICL implantation [25]. The accuracy of real-time intraoperative measurement of vaulting is critical to operation success. Indeed, the implantation of an ICL with the correct vaulting from the start will avoid complications (mechanical contact with the lens, pupillary block, iris touch, angle-closure glaucoma, anterior lens opacification, and early cataract [9-11]) and the need for reoperation and lens exchange [34]. This will save healthcare resources and money.

The traditional methods to determine vaulting based on WTW and ACD lead to about $20 \%$ of the patients being outside the accepted vaulting range $[35,36]$. The STS can also be used, but the relationship between the WTW and STS is affected by the degree of myopia [37-42]. OCT is a valuable tool for predicting vaulting $[19-21,25]$. In the present study, two eyes had too high vaulting, and two eyes had too low vaulting, leading to $4 \%$ of the eyes being outside the appropriate vaulting range. In addition, a $90-\mu m$ was observed between the intraoperative and the 1-month values, similar to the 100- $\mu \mathrm{m}$ difference observed by Torbey et al. [25]. This difference is likely due to the surgery itself, the use of irrigation, intraoperative adjustment in IOP, and the use of drugs to dilate the pupil, while the OCT at 1-month was measured on a physiological pupil. Indeed, vaulting is affected by pupil size [43]. Despite this difference, the intraoperative and 1-month vaulting values were highly correlated, as supported by Torbey et al. [25]. On the other hand, a study showed only a 7- $\mu \mathrm{m}$ difference between the intraoperative and 3-month vaulting values [44]. The wide-angle OCT image acquisition is associated with image distortion and could be a source of bias. In addition, this previous study [44] did not mention if a miotic agent was used before measurement.

Because of this difference in vaulting, it is difficult to determine whether an ICL should be exchanged when observing limit values. Nevertheless, as suggested by Torbey et al. [25], the ICL should be exchanged within the same operative session in the presence of extreme vaulting values, improving 
safety and patient satisfaction. Trancon et al. [26] elaborated a multivariable model that could predict vaulting and explain $34 \%$ of its variance; lens diameter, horizontal anterior chamber angle distance, CLR, ICL spherical equivalent, and patient age were independently associated with vaulting. In the present study, only the intraoperative vaulting was associated with the value at 1 month. This discrepancy could be due to the number of eyes, different OCT systems, and different drugs used for the eyes. Two eyes had ICL with too high vaulting and the ICL had to be exchanged in order to prevent short- and long-term complications like pupillary block, iris touch, angle-closure glaucoma, anterior lens opacification, and early cataract [9-11]. The rate of $2 \%$ reported here is within the numbers reported by the literature [1216]. The two eyes with low vaulting were not reoperated, but closer follow-up was performed. The low vaulting observed in two eyes might be due to the smaller pupil diameters, as shown by a previous study [45].

This study has limitations. The study was performed at a single hospital, and the number of included eyes was small. Because of the retrospective nature of the study, only the routine follow-up at 1 month was available, and the changes in vaulting over time could not be examined. Future studies should include more patients and should be prospectively conducted in order to include more follow-up time points and longer follow-up.

\section{Conclusion}

The RESCAN700 system can be used to perform intraoperative OCT to predict the vaulting value at 1 month. Therefore, the vaulting observed during surgery is probably predictive of the actual value that will be achieved, allowing optimization interventions to be carried out over abnormal intraoperative vaulting in time to obtain better results.

\section{List Of Abbreviations}




\begin{tabular}{|ll|}
\hline ACD & anterior chamber depth \\
\hline ACV & anterior chamber volume \\
\hline AS-OCT & anterior segment optical coherence tomography \\
\hline BCVA & best-corrected visual acuity \\
CLR & crystalline lens rise \\
\hline CVA & corrected visual acuity \\
\hline ECD & endothelial cell density \\
\hline ICL & implantable Collamer lens \\
\hline IOL & intraocular lens \\
\hline OCT & optical coherence tomography \\
\hline SE & spherical equivalent \\
\hline UCVA & uncorrected visual acuity \\
\hline WTW & white-to-white distance \\
\hline
\end{tabular}

\section{Declarations}

Ethics approval and consent to participate

Consent for publication

Not applicable.

\section{Availability of data and materials}

The datasets used and/or analysed during the current study are available from the corresponding author on reasonable request.

\section{Competing Interests}

All authors declare that they have no competing interests.

\section{Funding}

This study received no specific funding.

\section{Authors' contributions}

NG and XN Z carried out the studies, XN Z drafted the manuscript and participated in analysis, or interpretation of data. WJ Z participated in its design. NG and XN Z performed the statistical analysis. WJ 
Z participated in collecting data and acquisition. All authors read and approved the final manuscript.

\section{Acknowledgments}

The authors would like to thank all study participants who were enrolled in this study.

\section{References}

1. Holden BA, Wilson DA, Jong M, Sankaridurg P, Fricke TR, Smith EL, III, Resnikoff S. Myopia: a growing global problem with sight-threatening complications. Community eye health. 2015; 28:35.

2. Hashemi H, Fotouhi A, Yekta A, Pakzad R, Ostadimoghaddam H, Khabazkhoob M. Global and regional estimates of prevalence of refractive errors: Systematic review and meta-analysis. Journal of current ophthalmology. 2018; 30:3-22.

3. Alfonso JF, Baamonde B, Fernandez-Vega L, Fernandes P, Gonzalez-Meijome JM, Montes-Mico R. Posterior chamber collagen copolymer phakic intraocular lenses to correct myopia: five-year followup. Journal of cataract and refractive surgery. 2011; 37:873-80.

4. Igarashi A, Shimizu K, Kamiya K. Eight-year follow-up of posterior chamber phakic intraocular lens implantation for moderate to high myopia. American journal of ophthalmology. 2014; 157:532-9 e1.

5. Bloomenstein MR, Dulaney DD, Barnet RW, Perkins SA. Posterior chamber phakic intraocular lens for moderate myopia and hyperopia. Optometry. 2002; 73:435-46.

6. Shimizu K, Kamiya K, Igarashi A, Shiratani T. Early clinical outcomes of implantation of posterior chamber phakic intraocular lens with a central hole (Hole ICL) for moderate to high myopia. The British journal of ophthalmology. 2012; 96:409-12.

7. Shimizu K, Kamiya K, Igarashi A, Shiratani T. Intraindividual comparison of visual performance after posterior chamber phakic intraocular lens with and without a central hole implantation for moderate to high myopia. American journal of ophthalmology 2012;154:486-94 e481.

8. Packer M. Meta-analysis and review: effectiveness, safety, and central port design of the intraocular collamer lens. Clinical ophthalmology. 2016; 10:1059-77.

9. Chai J, Angunawela RI, Perera S, Tan D. Bilateral delayed nonpupillary block angle closure after insertion of phakic intraocular lens. Journal of cataract and refractive surgery. 2012; 38:722-3.

10. Senthil S, Choudhari NS, Vaddavalli PK, Murthy S, Reddy JC, Garudadri CS. Etiology and Management of Raised Intraocular Pressure following Posterior Chamber Phakic Intraocular Lens Implantation in Myopic Eyes. PloS one. 2016; 11:e0165469.

11. Gonvers M, Bornet C, Othenin-Girard P. Implantable contact lens for moderate to high myopia: relationship of vaulting to cataract formation. Journal of cataract and refractive surgery. 2003; 29:918-24.

12. Pesando PM, Ghiringhello MP, Di Meglio G, Fanton G. Posterior chamber phakic intraocular lens (ICL) for hyperopia: ten-year follow-up. Journal of cataract and refractive surgery. 2007; 33:1579-84. 
13. Kojima T, Yokoyama S, Ito M, Horai R, Hara S, Nakamura T, Ichikawa K. Optimization of an implantable collamer lens sizing method using high-frequency ultrasound biomicroscopy. American journal of ophthalmology. 2012; 153:632-7, 7 e1.

14. Zeng QY, Xie XL, Chen Q. Prevention and management of collagen copolymer phakic intraocular lens exchange: causes and surgical techniques. Journal of cataract and refractive surgery. 2015; 41:57684.

15. Fernandes P, Gonzalez-Meijome JM, Madrid-Costa D, Ferrer-Blasco T, Jorge J, Montes-Mico R. Implantable collamer posterior chamber intraocular lenses: a review of potential complications. Journal of refractive surgery. 2011; 27:765-76.

16. Rayner SA, Bhikoo R, Gray T. Spherical implantable collamer lenses for myopia and hyperopia: 126 eyes with 1-year follow up. Clinical \& experimental ophthalmology. 2010; 38:21-6.

17. Alfonso JF, Fernandez-Vega L, Lisa C, Fernandes P, Gonzalez-Meijome J, Montes-Mico R. Long-term evaluation of the central vault after phakic Collamer(R) lens (ICL) implantation using OCT. Graefe's archive for clinical and experimental ophthalmology = Albrecht von Graefes Archiv fur klinische und experimentelle Ophthalmologie. 2012; 250:1807-12.

18. Lindland A, Heger $H$, Kugelberg M, Zetterstrom C. Vaulting of myopic and toric Implantable Collamer Lenses during accommodation measured with Visante optical coherence tomography. Ophthalmology. 2010; 117:1245-50.

19. Alfonso JF, Fernandez-Vega-Cueto L, Alfonso-Bartolozzi B, Montes-Mico R, Fernandez-Vega L. FiveYear Follow-up of Correction of Myopia: Posterior Chamber Phakic Intraocular Lens With a Central Port Design. Journal of refractive surgery. 2019; 35:169-76.

20. Gonzalez-Lopez F, Bilbao-Calabuig R, Mompean B, Luezas J, Ortega-Usobiaga J, Druchkiv V. Determining the Potential Role of Crystalline Lens Rise in Vaulting in Posterior Chamber Phakic Collamer Lens Surgery for Correction of Myopia. Journal of refractive surgery. 2019; 35:177-83.

21. Nakamura T, Isogai N, Kojima T, Yoshida Y, Sugiyama Y. Implantable Collamer Lens Sizing Method Based on Swept-Source Anterior Segment Optical Coherence Tomography. American journal of ophthalmology. 2018; 187:99-107.

22. Binder S. Intra-operative OCT devices for ophthalmic use: an overview. Spektrum der Augenheilkd. 2014; 28:2-5.

23. Saad A, Guilbert E, Grise-Dulac A, Sabatier P, Gatinel D. Intraoperative OCT-Assisted DMEK: 14 Consecutive Cases. Cornea. 2015; 34:802-7.

24. Ehlers JP, Srivastava SK, Feiler D, Noonan Al, Rollins AM, Tao YK. Integrative advances for OCTguided ophthalmic surgery and intraoperative OCT: microscope integration, surgical instrumentation, and heads-up display surgeon feedback. PloS one. 2014; 9:e105224.

25. Torbey J, Mehanna CJ, Abdul Fattah M, Awwad ST. Comparison of intraoperative vs postoperative optical coherence tomography measurement of implantable collamer lens vaulting. Journal of cataract and refractive surgery. 2020; 46:737-41. 
26. Trancon AS, Manito SC, Sierra OT, Baptista AM, Serra PM. Determining vault size in implantable collamer lenses: preoperative anatomy and lens parameters. Journal of cataract and refractive surgery. 2020; 46:728-36.

27. Choi KH, Chung SE, Chung TY, Chung ES. Ultrasound biomicroscopy for determining visian implantable contact lens length in phakic IOL implantation. Journal of refractive surgery. 2007; 23:362-7.

28. Wang X, Zhou X. Update on Treating High Myopia With Implantable Collamer Lenses. Asia-Pacific journal of ophthalmology. 2016; 5:445-9.

29. Kobayashi A, Yokogawa H, Mori N, Sugiyama K. Visualization of precut DSAEK and pre-stripped DMEK donor corneas by intraoperative optical coherence tomography using the RESCAN 700. BMC ophthalmology. 2016; 16:135.

30. Eguchi H, Kusaka S, Arimura-Koike E, Tachibana K, Tsujioka D, Fukuda M, Shimomura Y. Intraoperative optical coherence tomography $(\operatorname{RESCAN}((\mathrm{R})) 700)$ for detecting iris incarceration and iridocorneal adhesion during keratoplasty. International ophthalmology. 2017; 37:761-5.

31. Das S, Kummelil MK, Kharbanda V, Arora V, Nagappa S, Shetty R, Shetty BK. Microscope Integrated Intraoperative Spectral Domain Optical Coherence Tomography for Cataract Surgery: Uses and Applications. Current eye research. 2016; 41:643-52.

32. Pahuja N, Shetty R, Jayadev C, Nuijts R, Hedge B, Arora V. Intraoperative Optical Coherence Tomography Using the RESCAN 700: Preliminary Results in Collagen Crosslinking. BioMed research international. 2015; 2015:572698.

33. Dusova J, Hejsek L, Stepanov A, Marak J, Jiraskova N. Intraoperative Optical Coherence Tomography in Vitreoretinal Surgery. Ceska a slovenska oftalmologie : casopis Ceske oftalmologicke spolecnosti a Slovenske oftalmologicke spolecnosti. 2017; 73:94-100.

34. Kaur M, Titiyal JS, Falera R, Sinha R, Sharma N. Indications for explant of implantable collamer lens. Eye (Lond). 2018; 32:838-40.

35. Lee DH, Choi SH, Chung ES, Chung TY. Correlation between preoperative biometry and posterior chamber phakic Visian Implantable Collamer Lens vaulting. Ophthalmology. 2012; 119:272-7.

36. Nam SW, Lim DH, Hyun J, Chung ES, Chung TY. Buffering zone of implantable Collamer lens sizing in V4c. BMC ophthalmology. 2017; 17:260.

37. Oh J, Shin HH, Kim JH, Kim HM, Song JS. Direct measurement of the ciliary sulcus diameter by 35megahertz ultrasound biomicroscopy. Ophthalmology. 2007; 114:1685-8.

38. Reinstein DZ, Archer TJ, Silverman RH, Rondeau MJ, Coleman DJ. Correlation of anterior chamber angle and ciliary sulcus diameters with white-to-white corneal diameter in high myopes using artemis VHF digital ultrasound. Journal of refractive surgery. 2009; 25:185-94.

39. Kawamorita T, Uozato H, Kamiya K, Shimizu K. Relationship between ciliary sulcus diameter and anterior chamber diameter and corneal diameter. Journal of cataract and refractive surgery. 2010; 36:617-24. 
40. Nemeth G, Hassan Z, Szalai E, Berta A, Modis L, Jr. Comparative analysis of white-to-white and angle-to-angle distance measurements with partial coherence interferometry and optical coherence tomography. Journal of cataract and refractive surgery. 2010; 36:1862-6.

41. Gao J, Liao RF, Li N. Ciliary sulcus diameters at different anterior chamber depths in highly myopic eyes. Journal of cataract and refractive surgery. 2013; 39:1011-6.

42. Biermann J, Bredow L, Boehringer D, Reinhard T. Evaluation of ciliary sulcus diameter using ultrasound biomicroscopy in emmetropic eyes and myopic eyes. Journal of cataract and refractive surgery. 2011; 37:1686-93.

43. Lee H, Kang SY, Seo KY, Chung B, Choi JY, Kim KS, Kim TI. Dynamic vaulting changes in V4c versus V4 posterior chamber phakic lenses under differing lighting conditions. American journal of ophthalmology. 2014; 158:1199-204 e1.

44. Titiyal JS, Kaur M, Sahu S, Sharma N, Sinha R. Real-time assessment of intraoperative vaulting in implantable collamer lens and correlation with postoperative vaulting. European journal of ophthalmology. 2017; 27:21-5.

45. Lee H, Kang DSY, Choi JY, Ha BJ, Kim EK, Seo KY, Kim TI. Analysis of pre-operative factors affecting range of optimal vaulting after implantation of 12.6-mm V4c implantable collamer lens in myopic eyes. BMC ophthalmology. 2018; 18:163.

\section{Figures}

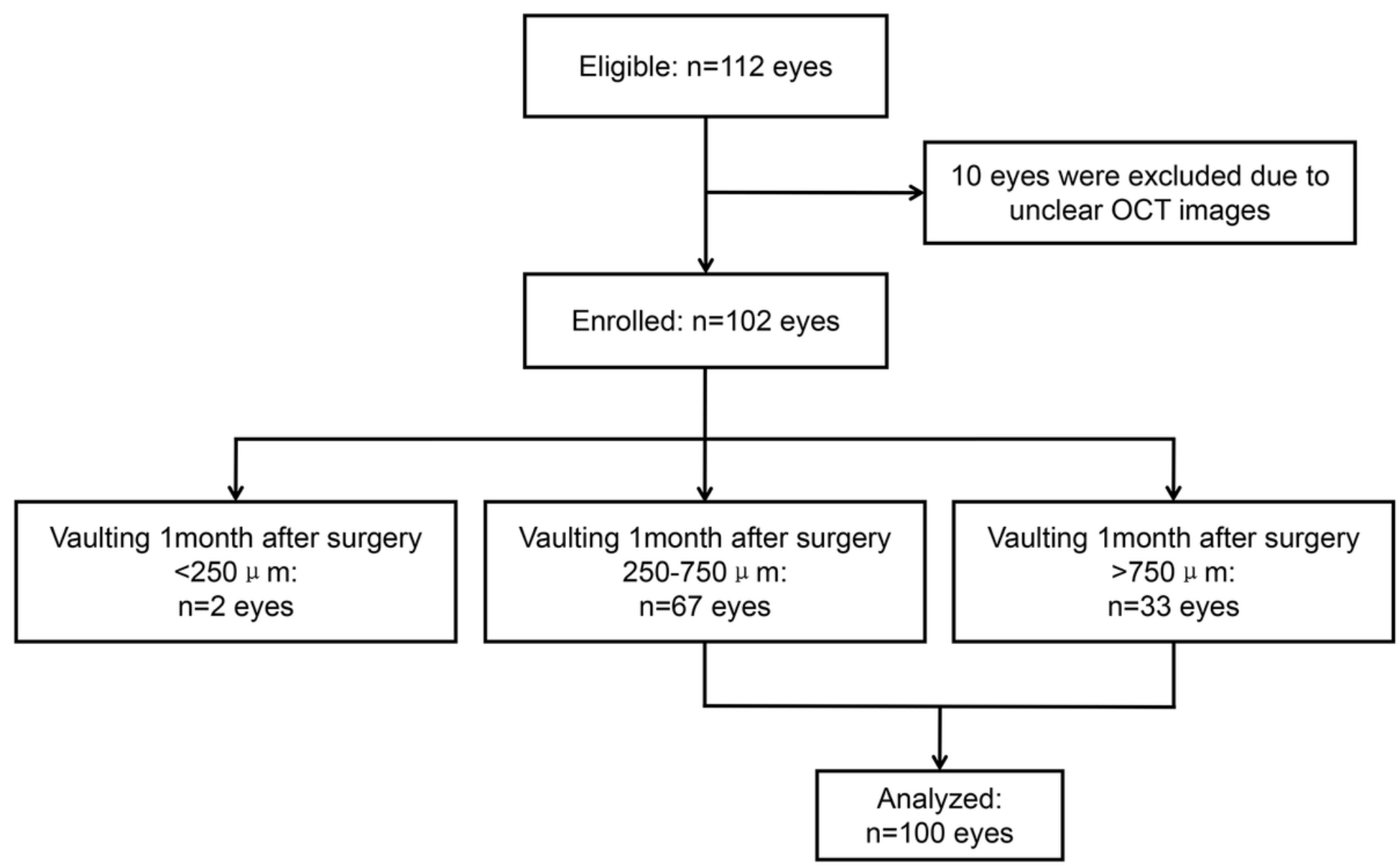


Figure 1

Patient flowchart.
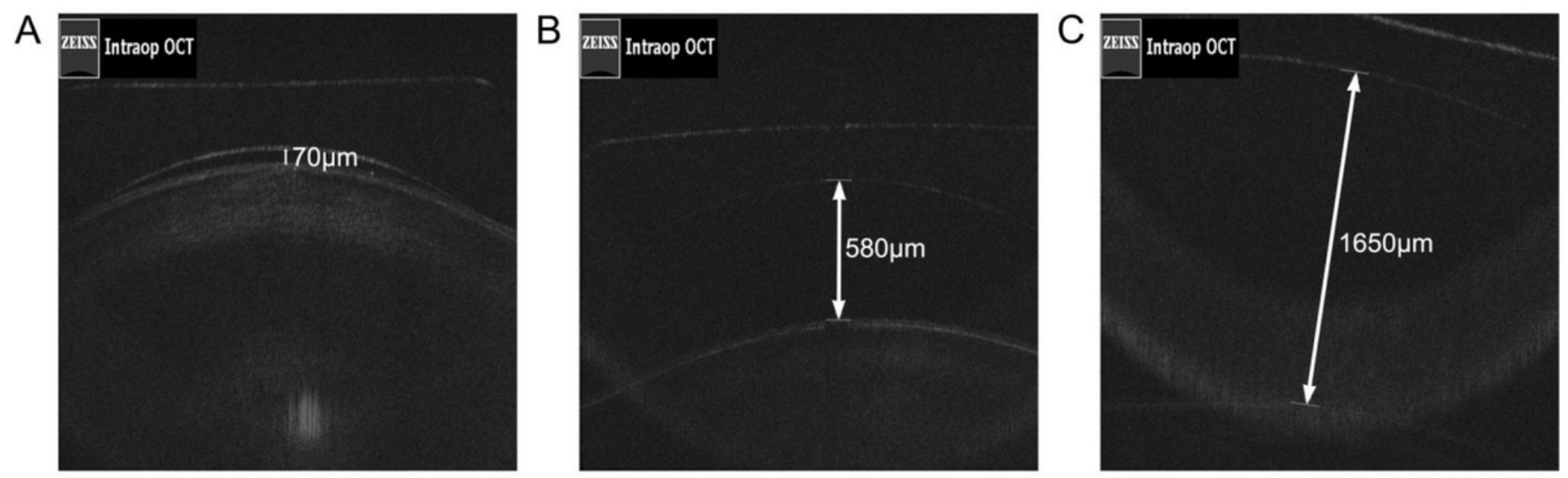

Figure 2

Typical figures for measuring vaulting (intraoperative). (A) Low intraoperative vaulting; (B) Normal intraoperative vaulting; (C) High intraoperative vaulting. 


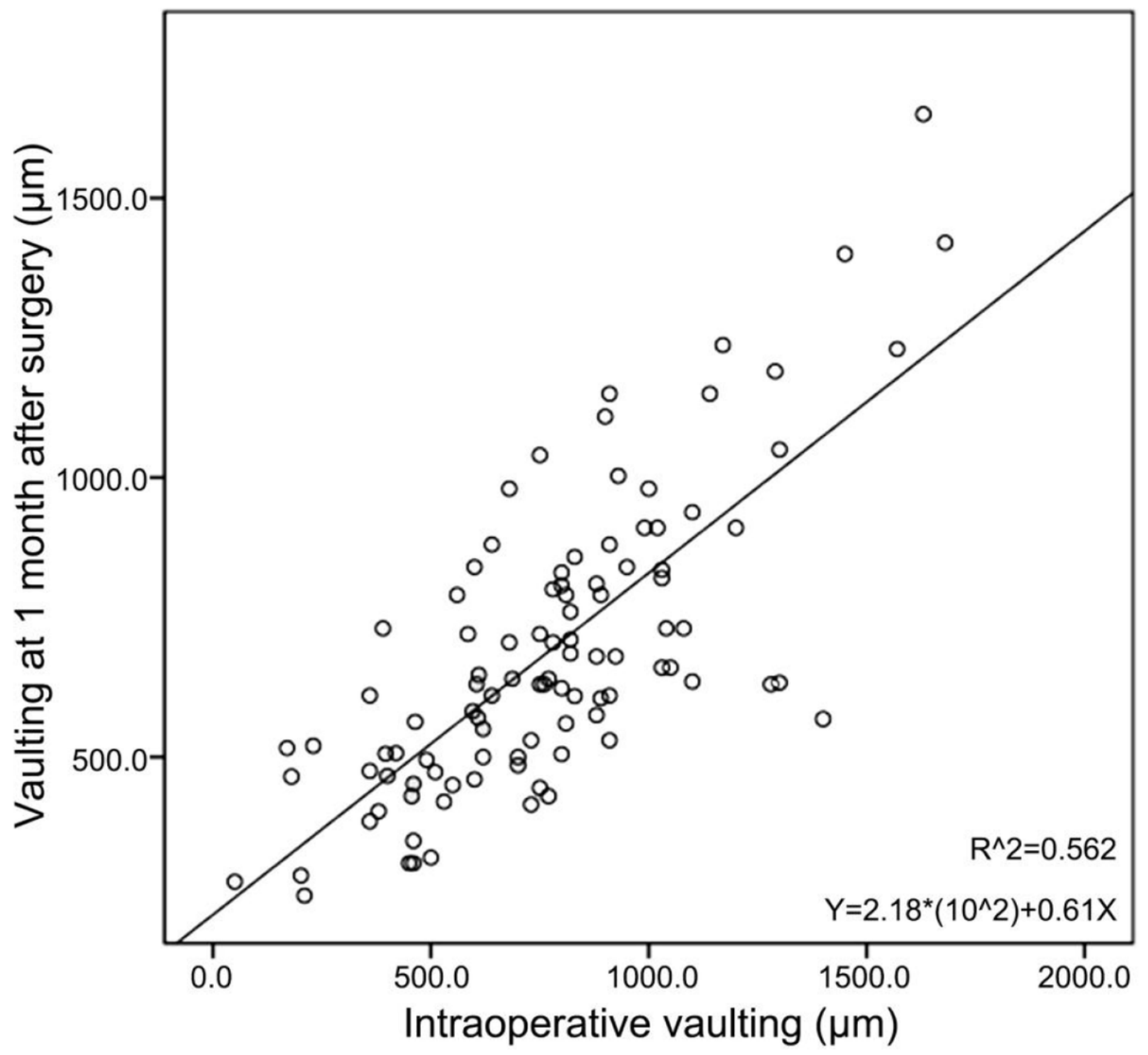

Figure 3

Linear correlation between intraoperative vaulting and the vaulting at 1 month after surgery. $X$-axis: intraoperative vaulting. Y-axis: vaulting at 1 month after surgery. 